Copyright (C) 2015 by Academic Publishing House Researcher

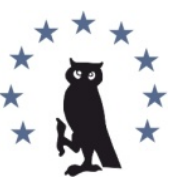

Published in the Russian Federation

European Researcher

Has been issued since 2010 .

ISSN 2219-8229

E-ISSN 2224-0136

Vol. 98, Is. 9, pp. 629-636, 2015

DOI: 10.13187/ er.2015.98.629

www.erjournal.ru

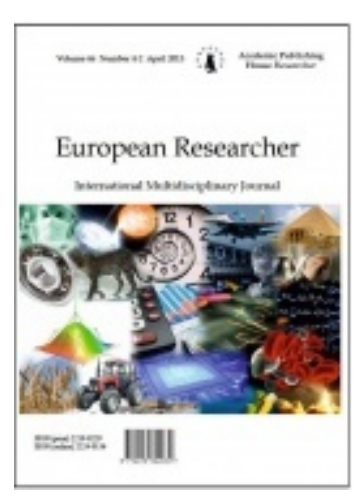

UDC 336.02

\title{
Cost Estimaition of "Tourist" Budget Services in Resort City of Sochi
}

\author{
E.E. Sinyavskaya
}

Sochi state university, Russian Federation

Sovetskaya Str. 26 a, Sochi city 354000

$\mathrm{PhD}$ (economic), Assistant Professor

E-mail: sutrfik@yandex.ru

\section{Abstract}

The article dwells upon the matters of tourist activity management on municipal level with the aim to achieve the most suitable development of the territory. J oint use by both permanent residents of the certain territory and tourists of great amount of resources, which form the usual inhabitable environment, creates the significant additional loading on local resources, which are financed from municipal treasury. Issuing of budget services by self-governing authorities of recreational and tourist regions is considered on the example of Sochi health resort. Analysis, which has been performed, allows separating and evaluating the "tourist component" of budget services. Services, used by tourists and paid by municipal entity budget, can be viewed as certain conventional export. Consequently, it is necessary to create the mechanism of compensation payments to budget for using collective services of mixed use by non-residents.

Keywords: recreation regions, budget expenditures of municipal formation, budget services, cost estimation of budget services, "tourist component" of budget services.

\section{Введение}

В Российской Федерации большое внимание уделяется развитию туризму, который должен обеспечивать высокие и устойчивые темпы экономического роста регионов, и рассматривается как важный источник финансовых доходов бюджетов регионов и муниципальных образований, специализирующихся на рекреационно-туристской деятельности, как средство повышения занятости и качества жизни населения. Так, туристский поток в Краснодарском крае в 2012 году превысил 11,3 млн. человек, а доходы от санаторнокурортного и туристского комплекса составили 63,6 млрд.рублей [1], которые стали основой формирования налоговых поступлений в бюджет. Вместе с тем, туристские потоки генерируют дополнительную нагрузку на региональные бюджетные услуги общего назначения. В этой связи особое значение приобретает регулирование туристской деятельности на региональном и муниципальном уровнях. Центральным звеном в регулировании на региональном и муниципальном уровне является управление процессами использования ресурсов общего назначения [2]. Это, в первую очередь, обусловлено необходимостью совместного использования постоянным населением данной территории и туристами большого числа бюджетных услуг, формирующих обычную жизненную среду в регионе. 


\section{Материалы и методы}

В основу методологии исследования потребления бюджетных услуг туристами и постоянным населением региона положены методы статистического анализа, методы экспертных оценок, экономико-математическое моделирование. Информационной базой исследования являются данные официальной статистики: паспорт муниципального образования города-курорта Сочи, материалы территориального управления Федеральной службы по статистике Краснодарского края и портала исполнительных органов государственной власти Краснодарского края.

\section{Обсуждение}

Теоретические и прикладные аспекты влияния туризма на социально-экономическую систему региона исследованы в трудах российских ученых В.Г. Гуляева [3], А.Б. Здоров [4], А.Б. Г.А. Карповой [5], А.А. Татаринова [6] и др. Население, расходуя больше денег на потребление различных благ, воздействует на производителей в рыночном сегменте, которые стремятся действовать более эффективно, чтобы выдержать рыночную конкуренцию. Выпуск бюджетных услуг органами регионального управления и местного самоуправления создает благосостояние так же, как и выпуск рыночного сектора, несмотря на то, что потребители либо не платят за эти услуги, либо платят номинальную цену.

Выпуск бюджетных услуг органов местного самоуправления рекреационно-туристских местностей рассмотрен на примере города-курорта Сочи. Источником информации о бюджетных услугах послужила статистика по исполнения бюджета муниципального образования (таблица 1).

\section{Исполнение бюджета города-курорта Сочи*)}

Таблица 1

\begin{tabular}{l|r|cc|c|c|c}
\hline \multirow{2}{*}{ Годы } & \multicolumn{3}{|c|}{ Доходы } & \multicolumn{3}{c}{ Расходы } \\
\cline { 2 - 7 } & тыс. pуб. & $\begin{array}{c}\text { в \% к } \\
\text { предшеств } \\
\text { ующему } \\
\text { году }\end{array}$ & $\begin{array}{c}\text { на душу } \\
\text { населения, } \\
\text { тыс. } \\
\text { ру6./чел }\end{array}$ & тыс. py6. & $\begin{array}{c}\text { в \% к } \\
\text { предшеств } \\
\text { ующему } \\
\text { году }\end{array}$ & $\begin{array}{c}\text { на душу } \\
\text { населения, } \\
\text { тыс. } \\
\text { ру6./чел }\end{array}$ \\
\hline 2008 & 8445109 & & 20,7 & 8826362 & & 21,6 \\
\hline 2009 & 11905574 & $40,98 \%$ & 28,8 & 10811051 & $22,49 \%$ & 26,2 \\
2010 & 14155175 & $18,90 \%$ & 33,8 & 14482916 & $33,96 \%$ & 34,6 \\
\hline 2011 & 14669919 & $3,64 \%$ & 34,2 & 13934345 & $-3,79 \%$ & 32,5 \\
2012 & 21160835 & $44,25 \%$ & 43,7 & 19269442 & $38,29 \%$ & 43,7 \\
\hline
\end{tabular}

*) рассчитано на основе данных $[7,8]$.

На протяжении последнего времени наблюдается абсолютный рост бюджетных доходов и расходов города-курорта Сочи, который сопровождается ростом бюджетных доходов и расходов на душу населения. Негативной тенденцией последних лет является снижение доли собственных доходов в бюджете, которая за последние пять лет сократилась почти в два раза и составила менее трети всех доходов бюджета. Собственные доходы покрывают расходы бюджета только на 35,85 \% (таблица 2), следовательно, бюджетная зависимость от внешних источников города Сочи возрастает.

За рассматриваемый период практически удвоилась бюджетная обеспеченность населения города Сочи с 21,6 тысяч рублей на одного жителя до 43,7 тыс. рублей. Расчет этого коэффициента базируется на численности постоянного населения муниципального образования. Расходы муниципального бюджета города Сочи, мало отличаются от соответствующих расходов в муниципальных образованиях, не специализирующихся на туризме. Вместе с тем, особенностью туризма является то, что одни и те же услуги органов местного самоуправления рекреационно-туристских местностей потребляются одновременно и местным населением и туристами. 
Динамика бюджетных показателей города-курорта Сочи*)

\begin{tabular}{|c|c|c|c|c|c|}
\hline Показатели & 2008 & 2009 & 2010 & 2011 & 2012 \\
\hline Бюджетные расходы, тыс. руб. & 8826362 & 10811051 & 14482915 & 13934344 & 19269441 \\
\hline Бюджетные доходы, тыс. руб. & 8445109 & 11905574 & 14155175 & 14669918 & 21160835 \\
\hline $\begin{array}{l}\text { - в том числе собственные } \\
\text { доходы бюджета }\end{array}$ & 5156000 & 5394370 & 5914991 & 6797497 & 6907530 \\
\hline $\begin{array}{l}\text { Доля собственшцгх доходов в } \\
\text { доходах бюджета, } \%\end{array}$ & 61,05 & 45,31 & 41,79 & 46,34 & 32,64 \\
\hline $\begin{array}{l}\text { Ірофишит/дефишит бюджета, } \\
\text { тыс. руб. }\end{array}$ & -381252 & 1094523 & -327740 & 735574 & 1891394 \\
\hline $\begin{array}{l}\text { Коэффициснт обсспсчсния } \\
\text { расходов собственньми } \\
\text { доходами, \% }\end{array}$ & 58,4 & 49,9 & 40,9 & 48,8 & 35,8 \\
\hline $\begin{array}{l}\text { Коэффициент бюджетной } \\
\text { обсспсчснности насслснил, } \\
\text { тыс. руб./ чел. }\end{array}$ & 21,6 & 26,2 & 34,6 & 32,5 & 43,7 \\
\hline
\end{tabular}

*) рассчитано на основе данных $[7,8]$.

При расчете стандартных коэффициентов бюджетной обеспеченности этот момент не учитывается, поэтому фактическая бюджетная обеспеченность ниже расчетной. Следовательно, традиционные методы оценки стоимости бюджетных услуг не отражают реальной ситуации.

В соответствии с теорией бюджетного федерализма, децентрализовано, на уровне муниципалитета должны приниматься решения, относящиеся к поставке тех общественных благ (услуг), выгоды от которых в основном локализуются на данной территории. В этом случае жители муниципального образования берут на себя ответственность за финансирование поставки локальных общественных благ. Однако в рекреационно-туристских местностях выгоды, приносимые общественным благом, не локализуются, так как потребителем общественных благ являются не только постоянные жители Сочи, но и те, кто прибывает в город на отдых. Это означает, что одна и та же городская среда является обычной средой жизни местного населения и средой пребывания посетителей (в том числе, туристов). Возникает проблема “безбилетника" [9], когда невозможно контролировать доступ к благу, а значит, децентрализованные решения, касающиеся желательного состава и количества, общественных благ, не подкрепляются децентрализованным финансированием из городского бюджета.

Туристские ресурсы в большинстве своем являются ресурсами смешанного назначения. Во многих случаях муниципалитеты рекреационно-туристских местностей вынуждены поддерживать состояние довольно экзотической городской среды, неся при этом иногда весьма значительные дополнительные расходы [11]. Необходимо финансировать выходящие из строя нестандартные элементы инфраструктуры, сохранять исторически сложившийся облик города, поддерживать экологию, поскольку это является одним из главных факторов привлечения туристов. При этом местное население фактически жертвует комфортом и несет значительные дополнительные расходы по тем же причинам.

Бюджетные расходы, направленные на воспроизводство локальных ресурсов, доступ к которым имеют не только местные жители, представляют для рекреационных регионов туристскую составляющую. Предлагается принципиальный подход к оценке итоговых показателей выпуска "туристских" бюджетных услуг в муниципальных образованиях рекреационно-туристской специализации, который состоит в следующем:

1. Определяется набор бюджетных расходов на развитие и содержание локальных ресурсов, потребляемых местным населением и посетителями. Состав бюджетных расходов на содержание локальных ресурсов смешанного назначения приведен в таблице 3. 
2. Определяется условная туристская доля, то есть доля потребляемых туристами ресурсов.

3. Рассчитывается стоимость "туристских" бюджетных услуг.

Оценка туристских долей может проводиться в два этапа.

На первом этапе рассчитывается базовая туристская доля для данной местности (города) с учетом численности посетителей рекреационно-туристского региона и среднего срока их пребывания на основе следующей формулы:

где: $S_{T}$ - базовая туристская доля;

$$
S_{T}=\frac{N_{T} * t}{N * 365+N_{T} * t}
$$

$N_{T}$ - численность туристов за отчетный год;

$\mathrm{t}$ - средний срок пребывания туристов, дней;

$\mathrm{N}$ - среднегодовая численность постоянного населения.

На втором этапе следует рассчитать индивидуальные туристские доли каждого вида бюджетных услуг. Для этого необходимо предварительно оценить поправочные коэффициенты (множители) по каждому виду бюджетных услуг. Поправочные коэффициенты должны рассчитываться на основе данных обследований соответствующих поставщиков бюджетных услуг. Поправочные коэффициенты отражают относительную интенсивность потребления каждого вида услуг туристами в сравнении с постоянным населением.

Если базовая туристская доля основывается на гипотезе о том, что туристы потребляют смешанные услуги с той же интенсивностью, что и местное население, то введение поправочного коэффициента позволяет скорректировать этот показатель, приблизив его к реальности.

$$
S_{R_{i}}=S_{T} * k_{i}
$$

где $S_{R_{i}}$ - индивидуальная туристская доля і - го вида бюджетных услуг;

$k_{i}$ - поправочный коэффициент (множитель) для і - го вида бюджетных услуг.

Поправочный коэффициент может быть больше единицы, если туристы потребляют услугу более интенсивно, чем местное население, или меньше единицы, если наоборот. Например, поправочный коэффициент для городского транспорта представляет собой отношение среднего количества поездок туристов по городу к среднему количеству поездок местного населения за один и тот же промежуток времени. Для определения конкретных значений поправочных коэффициентов требуется проведение специальных обследований, но, как показывает опыт, эти коэффициенты достаточно устойчивы во времени и могут использоваться в расчетах несколько лет.

$$
\begin{aligned}
& k_{i}=\frac{P_{T_{i}}}{P_{N_{i}}} \\
& S_{R_{i}}=S_{T} * \frac{P_{T_{i}}}{P_{N_{i}}}
\end{aligned}
$$

где $P_{T_{i}}$ - объем потребления бюджетной услуги і - го туристами;

где $P_{N_{i}}$ - объем потребления бюджетной услуги і - го местными жителями.

В этом случае стоимость "туристских" бюджетных услуг в муниципальных образованиях рекреационно-туристской специализации услуг будет рассчитываться как сумма бюджетных расходов на развитие и содержание локальных ресурсов, потребляемых и местным населением и туристами, скорректированных на индивидуальную туристскую долю, определенную для каждого вида бюджетных расходов:

$$
R=\sum_{i=1}^{n} R_{i} * S_{R_{i}}
$$

где R - стоимость "туристских" бюджетных услуг в муниципальных образованиях.

$$
R=\sum_{i=1}^{n}\left(R_{i} * S_{T} * \frac{P_{T_{i}}}{P_{N_{i}}}\right)
$$

Развитие и содержание локальных ресурсов, потребляемых местным населением и туристами, или услуги смешанного назначения финансируется за счет следующих статей муниципального бюджета: национальная безопасность и правоохранительная деятельность, транспорт, коммунальное хозяйство, охрана окружающей среды, культура, кинематография и средства массовой информации, здравоохранение. Из шести перечисленных видов 
бюджетных услуг первые четыре - охрана общественного порядка (органы внутренних дел), транспорт, коммунальное хозяйство и охрана окружающей среды - относятся к коллективным услугам. Культура, кинематография и средства массовой информации, а также здравоохранение - это преимущественно индивидуальные услуги.

Результаты. Оценка стоимости "туристских" бюджетных услуг в городе-курорте Сочи осуществлена на основе данных администрации города и представлена в таблице 3 .

Таблица 3

Расчет стоимости "туристских" бюджетных услуг по городу-курорту Сочи

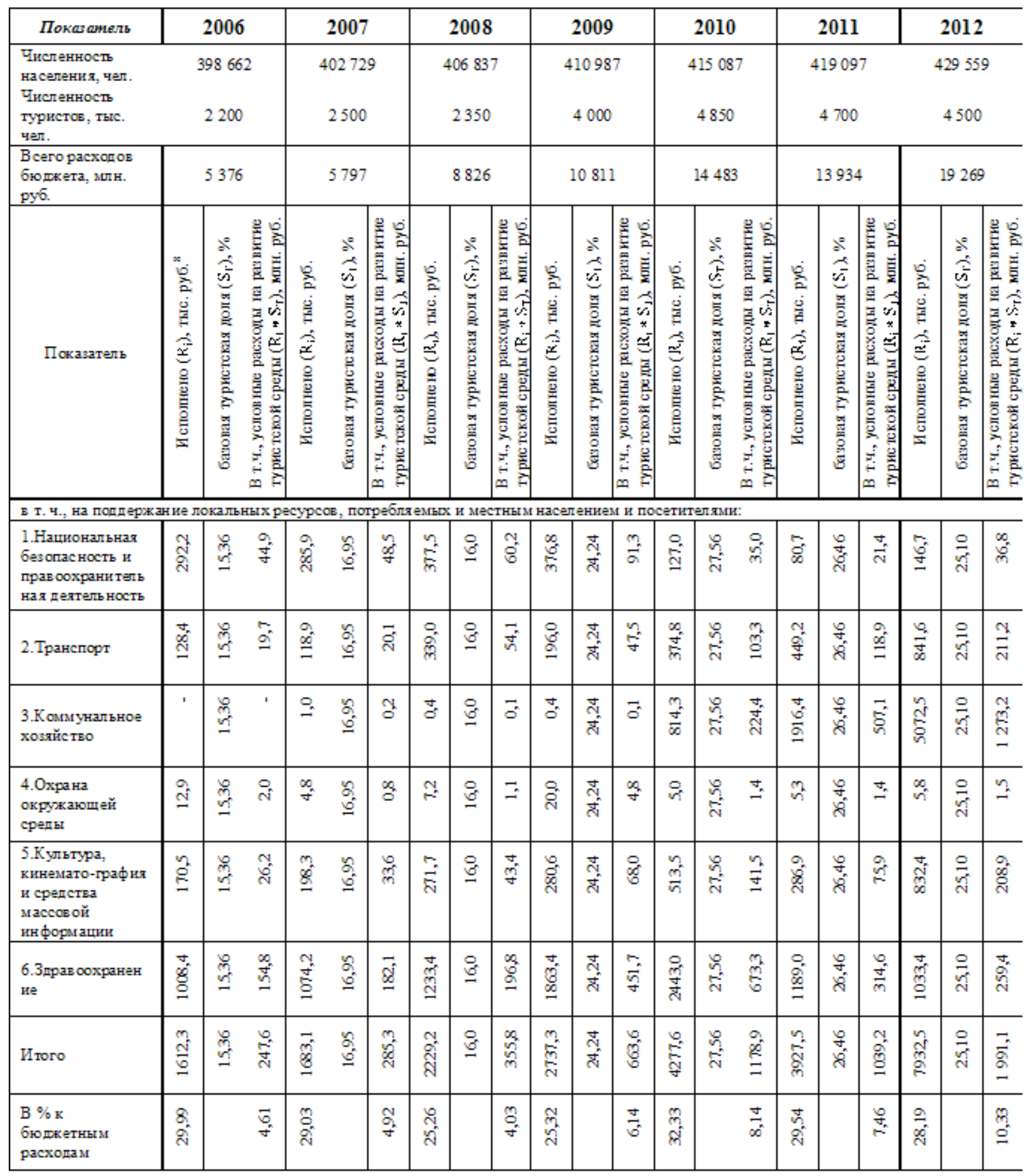

*) рассчитано на основе данных $[7,8,12]$. 
На протяжении рассматриваемого периода расходы бюджета города Сочи по этим статьям возросли в 4,9 раза в абсолютном выражении, тогда как их доля в общих расходах муниципального бюджета практически не изменилась и составляет около 30 \%. Базовая туристская доля услуг смешенного назначения возросла с 15,36 \% в 2006 году до 25,10 \% в 2012 году (рисунок 1).

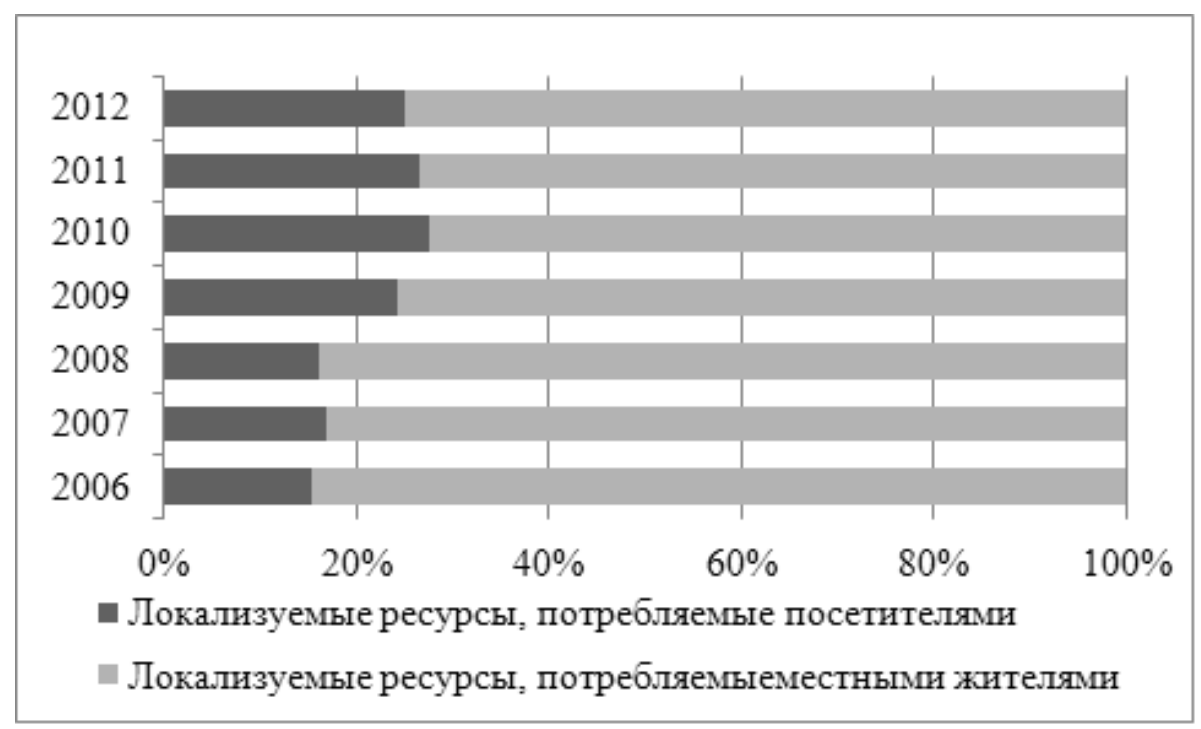

Рис. 1. Распределение локальных ресурсов по потребителям

Анализ показал наличие тенденции, в соответствии с которой все меньше услуг смешанного назначения приходится на потребление местных жителей и все больше - на туристов, посещающих город Сочи. Интересно отметить, что туристская доля в советский период в Сочи в 1989 году составляла 30,25 \%. Расчет базировался на следующих показателях: количество туристов с учетом до счета статистически ненаблюдаемого потока 3,8 млн. человек при средней продолжительности пребывания 15 дней и численности постоянного населения 360 тысяч человек.

В целом в 2012 году доля туристского выпуска органов местного самоуправления оценивается в 1991,1 млн. рублей или 10,33\% всех бюджетных расходов против 247,6 млн. рублей или 4,61 \% в 2006 году.

Обеспеченность локальными ресурсами населения в 2012 году составила 18,4 тысячи рублей в год на жителя. Если принимать во внимание распределение локальных ресурсов между постоянным населением и туристами, то фактическая обеспеченность этими ресурсами местного населения составляет 13,8 тыс. рублей на потребителя или на 25 \% ниже.

\section{Заключение}

Туристы создают значительную дополнительную нагрузку на локальные на ресурсы, которые финансируются за счет местного бюджета. Поскольку эти локальные услуги потребляются нерезидентами, их можно отнести к трансфертам внешнему миру в натуральной форме, поскольку для потребителей они бесплатны. Вместе с тем, поскольку бюджетные услуги, потребленные туристами, в конечном счете, оплачиваются бюджетом муниципального образования, то их можно также рассматривать как некий условный экспорт, реализуемый по цене, равной стоимости бюджетных расходов. В этом случае величина этих бюджетных расходов условно отражает стоимость потребленных туристами локальных ресурсов. Но тогда должен существовать механизм изъятия в бюджет муниципального образования компенсационных платежей за пользование нерезидентами коллективными услугами смешанного назначения. Объемы такой компенсации можно оценить на основе предложенной методики. В частности, в приведенном расчете суммарная стоимость компенсации в 2012 году должна была бы составлять около двух миллиардов рублей. Механизмы компенсации могут строиться на принципах пропорционального участия муниципального образования с предпринимательскими структурами, но желательно без 
создания дополнительной налоговой нагрузки. Возможно, разрешение этой проблемы потребует принятия институциональных решений, а именно, упрощения процедур в сфере предпринимательства при одновременном ужесточении налоговых обязательств.

\section{Примечания:}

1. Постановление главы администрации (губернатора) Краснодарского края от 11 октября 2013 г. N 1168 "Об утверждении государственной программы Краснодарского края "Развитие санаторно- курортного и туристского комплекса". Министерство экономики Краснодарского края. [Электронный ресурс] Режим доступа в Интернет: http:// economy.krasnodar.ru/gos-prog-kk/ perech-gp/files/0608_postan_11102013_1168.docx

2. Татаринов А.А., Татаринова С.И. Функции органов управления в области использования туристских ресурсов // Социально-экономическое и инновационное развитие Юга России. Материалы конференции. Сочи: РИО СНИЦ РАН, 2009. 197с. 2010. 304c.

3. Гуляев В.Г. Туризм: экономика и социальное развитие. М.: Финансы и статистика,

4. Здоров А.Б. Экономика туризма. М., Финансы и статистика. 2007. 272с.

5. Экономика и управление туристской деятельностью (в 2 томах) / под общ. ред. Карповой Г.А., Хоревой Л.В. Спб, СПбГУЭФ, 2011. 286с.

6. Татаринов А.А. Методология оценки и анализа экономики рекреационнотуристского региона. Сочи : СГУТиК, 1998. 92с.

7. Паспорт муниципального образования город-курорт Сочи. База данных: показатели муниципальных образований. Федеральная служба государственной статистики. [Электронный ресурс] Режим доступа: http://www.gks.ru/scripts/ db_inet2/passport /pass. aspx?base $=$ munst03\& $r=3726000$.

8. База данных показателей муниципальных образований. Краснодарстат. [Электронный ресурс] Режим доступа в Интернет: http://krsdstat.gks.ru

9. Экономика общественного сектора: учебник для вузов / под ред. Л.И. Якобсона, М.Г. Колосницыной. 3-е изд., перераб. и доп. М.: Издательство Юрайт, 2014. 558 с.

10. Портал исполнительных органов государственной власти Краснодарского края. [Электронный ресурс] Режим доступа в Интернет: http:// www.krasnodar.ru

11. Синявская Е.Е., Татаринова С.И. Анализ состояния муниципального бюджета и туристских бюджетных услуг г. Сочи. / Социально-экономические и технологические проблемы устойчивого развития Юга России: сб. науч. тр. Краснодар: Экоинвест, 2009.

12. Кубанский информационный портал. [Электронный ресурс] Режим доступа в Интернет: http:// kuban.info

\section{References:}

1. Postanovlenie glavy administratsii (gubernatora) Krasnodarskogo kraya ot 11 oktyabrya 2013 g. N 1168 "Ob utverzhdenii gosudarstvennoi programmy Krasnodarskogo kraya "Razvitie sanatorno- kurortnogo i turistskogo kompleksa". Ministerstvo ekonomiki Krasnodarskogo kraya. [Elektronnyi resurs] Rezhim dostupa v Internet: http://economy.krasnodar.ru/gos-progkk/ perechgp/files/ 0608 postan 11102013 1168.docx

2. Tatarinov A.A., Tatarinova S.I. Funktsii organov upravleniya v oblasti ispol'zovaniya turistskikh resursov // Sotsial'no-ekonomicheskoe i innovatsionnoe razvitie Yuga Rossii. Materialy konferentsii. - Sochi: RIO SNITs RAN, 2009. 197s.

3. Gulyaev V.G. Turizm: ekonomika i sotsial'noe razvitie. M.: Finansy i statistika, 2010. 304 s.

4. Zdorov A.B. Ekonomika turizma. M., Finansy i statistika. 2007. 272 s.

5. Ekonomika i upravlenie turistskoi deyatel'nost'yu (v 2 tomakh) / pod obshch. red. Karpovoi G.A., Khorevoi L.V. Spb, SPbGUEF, 2011. 286s.

6. Tatarinov A.A. Metodologiya otsenki i analiza ekonomiki rekreatsi- onno-turistskogo regiona. Sochi : SGUTiK, 1998. 92 s.

7. Pasport munitsipal'nogo obrazovaniya gorod-kurort Sochi. Baza dannykh: pokazateli munitsipal'nykh obrazovanii. Federal'naya sluzhba gosudarstvennoi statistiki. [Elektronnyi resurs] Rezhim dostupa: http://www.gks.ru/scripts/db_inet2/passport/ pass.aspx?base=munst03\&r $=3726000$. 
8. Baza dannykh pokazatelei munitsipal'nykh obrazovanii. Krasnodarstat. [Elektronnyi resurs] Rezhim dostupa v Internet: http:/ /krsdstat.gks.ru

9. Ekonomika obshchestvennogo sektora : uchebnik dlya vuzov / pod red. L. I. Yakobsona, M. G. Kolosnitsynoi. 3-eizd., pererab. i dop. M.: Izdatel'stvo Yurait, 2014. 558s.

10. Portal ispolnitel'nykh organov gosudarstvennoi vlasti Krasnodarskogo kraya. [Elektronnyi resurs] Rezhim dostupa v Internet: http:// www.krasnodar.ru

11. Sinyavskaya E.E., Tatarinova S.I. Analiz sostoyaniya munitsipal'nogo byudzheta i turistskikh byudzhetnykh uslug g. Sochi. / Sotsial'no-ekonomicheskie i tekhnologicheskie problemy ustoichivogo razvitiya Yuga Rossii: sb. nauch. tr. Krasnodar: Ekoinvest, 2009.

12. Kubanskii informatsionnyi portal. [Elektronnyi resurs] Rezhim dostupa v Internet: http://kuban.info

УДК 336.02

\section{Оценка стоимости "туристских" бюджетных услуг в городе-курорте Сочи}

\section{Е.Е. Синявская}

Сочинский государственный университет, Российская Федерация

354000 Краснодарский край, г. Сочи, ул. Советская, 26 а

Кандидат экономических наук, доцент

E-mail: sutrfik@yandex.ru

Аннотация. В статье рассматриваются вопросы управления туристской деятельностью на муниципальном уровне с целью достижения оптимального развития территории. Совместное использование постоянным населением данной территории и туристами большого числа ресурсов, формирующих обычную жизненную среду в регионе, создает значительную дополнительную нагрузку на локальные на ресурсы, которые финансируются за счет местного бюджета. Выпуск бюджетных услуг органов местного самоуправления рекреационно-туристских местностей рассмотрен на примере города-курорта Сочи. Проведенный анализ позволил выделить и оценить «туристскую составляющую» бюджетных услуг. Услуги, потребленные туристами и оплачиваемые бюджетом муниципального образования, можно рассматривать как некий условный экспорт, а значит, возникает необходимость в создании механизма компенсационных платежей в бюджет за пользование нерезидентами коллективными услугами смешанного назначения.

Ключевые слова: рекреационные регионы, расходы бюджета муниципального образования, бюджетные услуги, оценка стоимости «туристских» бюджетных услуг. 